\title{
Injectable fillers: imaging features and related complications
}

\author{
Mohsen Ahmed Abdelmohsen(D)
}

\begin{abstract}
Background: Injectable fillers are currently widely used in the clinical practice; there are many indications for injectable fillers including facial and gluteal rejuvenation, management of post-traumatic facial disfiguring, and pathological volumetric loss secondary to certain disease medications like human immune deficiency virus (HIV) medications.

Radiologists should be familiar with the specific imaging features of the injectable fillers, characteristic anatomical locations, and possible complications to avoid diagnostic pitfalls especially when incidentally discovered while imaging of other pathological process like neoplastic work up or granulomatous lesions follow-up.

Results: The study included 48 patients ( 45 females and 3 males): 44 patients with facial injectable fillers and four patients with pelvic injectable fillers.

Of the 48 patients, 37 patients showed unremarkable fillers features with normal morphological features and anatomical distribution, and eleven patients showed complications: six patients showed one complication, and five patients showed more than one complications.

Dedicated fillers imaging study was done in 22 patients, while in the other 26 patients, imaging was done for other reasons, and fillers were notified and documented.

Magnetic resonance imaging (MRI) was done for 46 patients; two patients were subjected to combine ultrasonographic and CT examinations with no clinical indication for MRI study assessment.

Conclusion: Magnetic resonance imaging (MRI) is an effective tool for evaluation of facial and gluteal region fillers with delineation of their imaging features and related potential complications.

Differentiation between fillers and neoplastic or granulomatous lesions could be accurately done with MRI.
\end{abstract}

Keywords: Injectable fillers, Nasolabial fold, Fillers complications, Migration, Abscess, Magnetic resonance imaging (MRI)

\section{Background}

Injectable fillers are currently widely used in the clinical practice; there are many indications for injectable fillers including facial and gluteal rejuvenation, management of post-traumatic facial and pelvic disfiguring as well as management of pathological volumetric loss secondary to certain disease medications like human immune deficiency (HIV) medications [1].

Correspondence: Mohsenmohsenmd@yahoo.com

Department of Radio-diagnosis and Intervention, Faculty of Medicine, University of Alexandria, 10 Shamplion street, Elazareeta, Alexandria, Egypt
Facial aging results from a combination of changes that involve the skin (e.g., wrinkling, dyspigmentation, and vascular changes) and underlying tissues. A progressive loss of tissue volume due to the atrophy of subcutaneous fat, as well as a reduction in structural support due to bone remodeling, contributes significantly to facial aging; the aging face becomes framed by bony contour and wrapped with thin skin resulting in deflated and fallen appearance $[1,2]$.

HIV-associated lipodystrophy is a syndrome that occurs in HIV-infected patients who are being treated with antiretroviral medications, although the term HIV-
Springer Open (c) The Author(s). 2020 Open Access This article is licensed under a Creative Commons Attribution 4.0 International License, which permits use, sharing, adaptation, distribution and reproduction in any medium or format, as long as you give appropriate credit to the original author(s) and the source, provide a link to the Creative Commons licence, and indicate if changes were made. The images or other third party material in this article are included in the article's Creative Commons licence, unless indicated otherwise in a credit line to the material. If material is not included in the article's Creative Commons licence and your intended use is not permitted by statutory regulation or exceeds the permitted use, you will need to obtain permission directly from the copyright holder. To view a copy of this licence, visit http://creativecommons.org/licenses/by/4.0/. 
associated lipodystrophy refers to abnormal central fat accumulation (lipohypertrophy) and localized loss of fat tissue (lipoatrophy) [2, 3].

Fillers can be classified into short-term fillers (lasting 0-3 months), for example, collagen; medium term (lasting for 3-12 months), for example, hyaluronic acid; and long-term fillers (from 12 months to indefinitely), for example, silicone [2].

In the routine practice, fillers are going to be common incidental findings in the routine MRI and CT examinations done for other indications, the most important when done for metastatic work up [3].

Radiologists should be familiar with the specific imaging features of the injectable fillers; most of the fillers have similar imaging appearance in MRI study due to high water contents (displaying T1WI hypointense signal, T2WI hyperintense signal, lack of diffusion restriction, lack of enhancement); some fillers show filler specific imaging features: lipofilling with the specific fat signal and characteristic fat suppression on fat suppressed sequence; silicon hyperintense signal in silicon only sequence-using DIXON method-is pathognomonic for silicon filler. Calcium hydroxyapatite filler shows characteristic hyperdensity in CT studies due to presence of calcium salts [1-3].

Radiologists should be familiar with the characteristic anatomical locations (the common locations include nasolabial folds, superficial medial and middle cheek fat compartment, peri-oral region, glabella, and gluteal subcutaneous fat) and possible complications to avoid diagnostic pitfalls especially when incidentally discovered while imaging of other pathological process like neoplastic work up or granulomatous lesions follow-up. Radiologists should avoid false-positive diagnosis of neoplastic lesions and at the same time to avoid missing neoplastic lesions masked by the injectable fillers $[4,5]$.

Although considered safe by many institutions, fillers are associated with multiple potential complications, which can be classified into short-term complications and long-term complications [2, 6].

Short-term complications include allergic reaction (mostly in collagen injectables), iatrogenic infection, over injection, and maldistribution of the fillers, while longterm complications include abscess development, foreign body granulomas, migration into distant parts, and scarring with disfigurement $[2,6]$.

Cross-sectional imaging techniques can detect the fillers based on their imaging features and characteristic locations as well as the related complications thus guiding for safe clinical management plans [7].

\section{Aim of the work}

The aim of the work was to assess the role of crosssectional imaging techniques in evaluation of the imaging features of injectable fillers and detection of their potential complications.

\section{Methods}

This is an analysis of 48 patients (mean age 40.6, range 22 years) with injectable filler injection either indicated

Table 1 Distribution of the studied patients according to different parameters

\begin{tabular}{|c|c|c|}
\hline & Number of the patients $(n, 48)$ & Percentage (\%) \\
\hline \multicolumn{3}{|l|}{ Age } \\
\hline 30 to less than 40 & 14 & 29.1 \\
\hline \multicolumn{3}{|l|}{ Standard deviation (SD), 4.8} \\
\hline \multicolumn{3}{|l|}{ Range, 7} \\
\hline 40 to less than 50 years & 14 & 29.1 \\
\hline \multicolumn{3}{|l|}{ Standard deviation (SD), 2.3} \\
\hline \multicolumn{3}{|l|}{ Range, 7} \\
\hline 50 to less than 60 years & 20 & 41.6 \\
\hline \multicolumn{3}{|l|}{ SD, 3.2 years } \\
\hline \multicolumn{3}{|l|}{ Range, 9} \\
\hline \multicolumn{3}{|l|}{ Indications of the imaging study } \\
\hline To study fillers and potential complications & 22 & 45.8 \\
\hline Incidentally noted in imaging work up for lymphoma & 10 & 20.8 \\
\hline Incidentally noted in imaging work up for headache & 16 & 33.3 \\
\hline \multicolumn{3}{|l|}{ Location of fillers } \\
\hline Facial & 44 & 91.66 \\
\hline Gluteal region & 4 & 8.33 \\
\hline
\end{tabular}



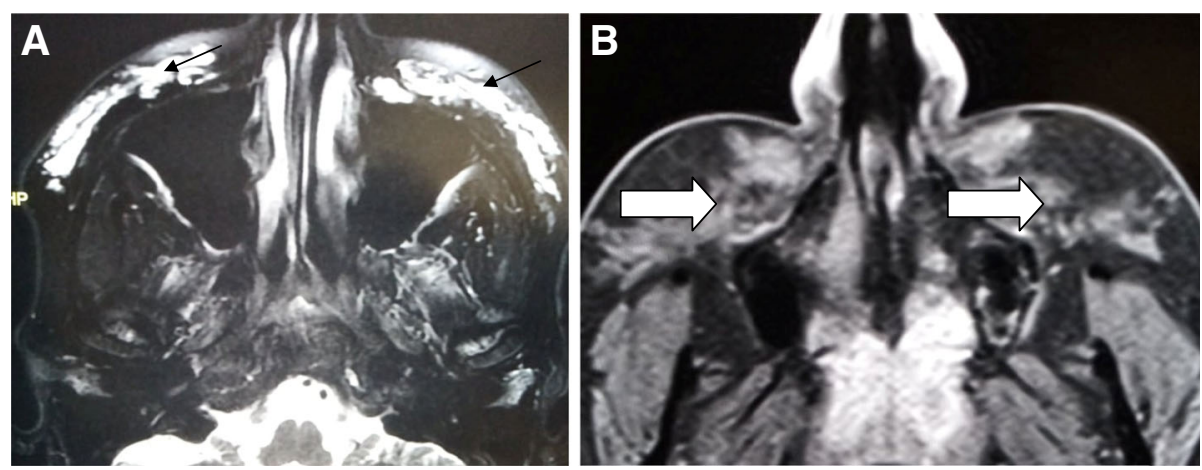

Fig. 1 a T2 Dixon FSE with fat suppression and $\mathbf{b}$ post contrast T1 Dixon with fat suppression showing expected distribution and morphology of the facial fillers, in the medial and middle superficial cheek compartment, high signal in T2WI due to high water contents (arrows in a), no appreciable enhancement following contrast injection (open arrow in b)

for post-traumatic disfigurement (in nine patients) or for cosmetic indications (39 patients).

Forty-six patients were subjected to dedicated MRI study, and two patients are subjected to ultrasonographic study followed by CT examination.

\section{Inclusion criteria}

The inclusion criteria are as follows:

1. More than 18 years with history of fillers injection with filler-related complaints

2. Incidentally detected fillers in patients underwent imaging for other indications (e.g., MRI study of the brain and paranasal sinuses)

\section{Exclusion criteria}

General contra indications for MRI and CT studies, all the patients were subjected to thorough history taking and dedicated clinical examination. Communication with the clinicians regarding the location and distribution of the fillers was done; trials to reach full clinical details were done (for example, silicon injection, type of silicon injection was sterile liquid silicon, amounts were few drops and were injected in micro droplet technique, and duration was about $15 \mathrm{~min}$ ).

Forty-six patients (out of 48 patients sample) were examined with a Siemens Magnetom 1.5 Tesla MRI, with small field of view (voxel size $0.3 \times 0.3 \times 4.0 \mathrm{~mm}-0.5 \times$ $0.5 \times 4.0 \mathrm{~mm})$. Thin slices $(3-4 \mathrm{~mm})$ were across axial and coronal planes. The following sequences were used: T1 Dixon fast spin echo (FSE) sequence non-contrast (TR $561.0 \mathrm{~ms}$, TE $79.0 \mathrm{~ms}$, flip angle $150^{\circ}$ ), with and without FS; T2 Dixon FSE non-contrast (TR $3800.0 \mathrm{~ms}$, TE $103.0 \mathrm{~ms}$, flip angle $160^{\circ}$ ), with and without FS; and T1 Dixon FSE axial and coronal acquisitions were used after gadolinium injection (TR $576.0 \mathrm{~ms}$, TE $11 \mathrm{~ms}$, flip angle $131^{\circ}$ ), with and without FS, diffusion weighted sequence ( $b$ values 50,500, 1000) with calculated ADC map, approximate total scan time of $45 \mathrm{~min}$ [8]. Two patients with abscess formation were subjected to ultrasonography (US) followed by CT examination without MRI study, and diagnosis confirmed by US guided aspiration.

Radiology consultant interpreted the data at Siemens work station; all images were read by M.A. with 6 years post medical doctorate (MD) experience.

Table 2 Diagnostic features of fillers in the studied patients

\begin{tabular}{|c|c|c|}
\hline Imaging features & Injectable fillers & Lipofilling \\
\hline T1 FSE & Hypointense & Hyperintense \\
\hline T2 FSE & Hyperintense due to high water contents & Hyperintense \\
\hline $\begin{array}{l}\text { Fat suppression sequence (Dixon method water } \\
\text { only sequence) }\end{array}$ & No fat suppression & Suppression of signal \\
\hline Diffusion weighted imaging & No restricted diffusion & No diffusion restriction \\
\hline Contrast enhanced sequences & $\begin{array}{l}\text { No enhancement, thin rim enhancement likely due to soft } \\
\text { tissue reactive changes }\end{array}$ & $\begin{array}{l}\text { No enhancement, thin rim } \\
\text { enhancement likely due to } \\
\text { soft tissue reactive changes }\end{array}$ \\
\hline Common locations & $\begin{array}{l}\text { Nasolabial fold } \\
\text { Medial and middle cheek superficial fat compartments } \\
\text { Peri-oral region }\end{array}$ & Gluteal regions \\
\hline
\end{tabular}


Table 3 Distribution of the studied patients according to the injectable fillers complications

\begin{tabular}{lcc}
\hline & Number of the patients $(n, 48)$ & Percentage $(\%)$ \\
\hline Complications & $\mathbf{1 1}$ & $\mathbf{2 3}$ \\
Asymmetry & 7 & 63 \\
Cellulitis & 1 & 9.09 \\
Abscess & 2 & 18.18 \\
Migration & 4 & 36.36 \\
Scarring & 2 & 18.18 \\
No complications & 37 & 77
\end{tabular}

$N B$ more than one complication noted in five patients

All the MRI and CT data are interpreted after gaining the clinical data from the referring clinicians.

Diffusion weighted sequence (b value $50,500,1000$ ) with calculated ADC map together with contrast enhanced sequence were the methodological parameters of choice in differentiation between the fillers and metastatic/neoplastic lesions, the ADC cutoff point chosen was $0.9 \times 10^{-3} \mathrm{~mm}^{2} / \mathrm{sec}[8]$.

Statistical Analysis: Qualitative data were described using numbers and percent.

\section{Ethics approval and consent to participate}

Approval for this study was obtained from the Research Ethics Committee of our institute. All study procedures were carried out in accordance with the Declaration of Helsinki regarding research involving human subjects.

\section{Results}

The study included 48 patients: 45 females (93.7\%) and 3 males $(6.25 \%)$.

There are 14 patients $(29.1 \%)$ between 30 less than 40 years, 14 patients $(29.1 \%)$ between 40 less than 50 years,

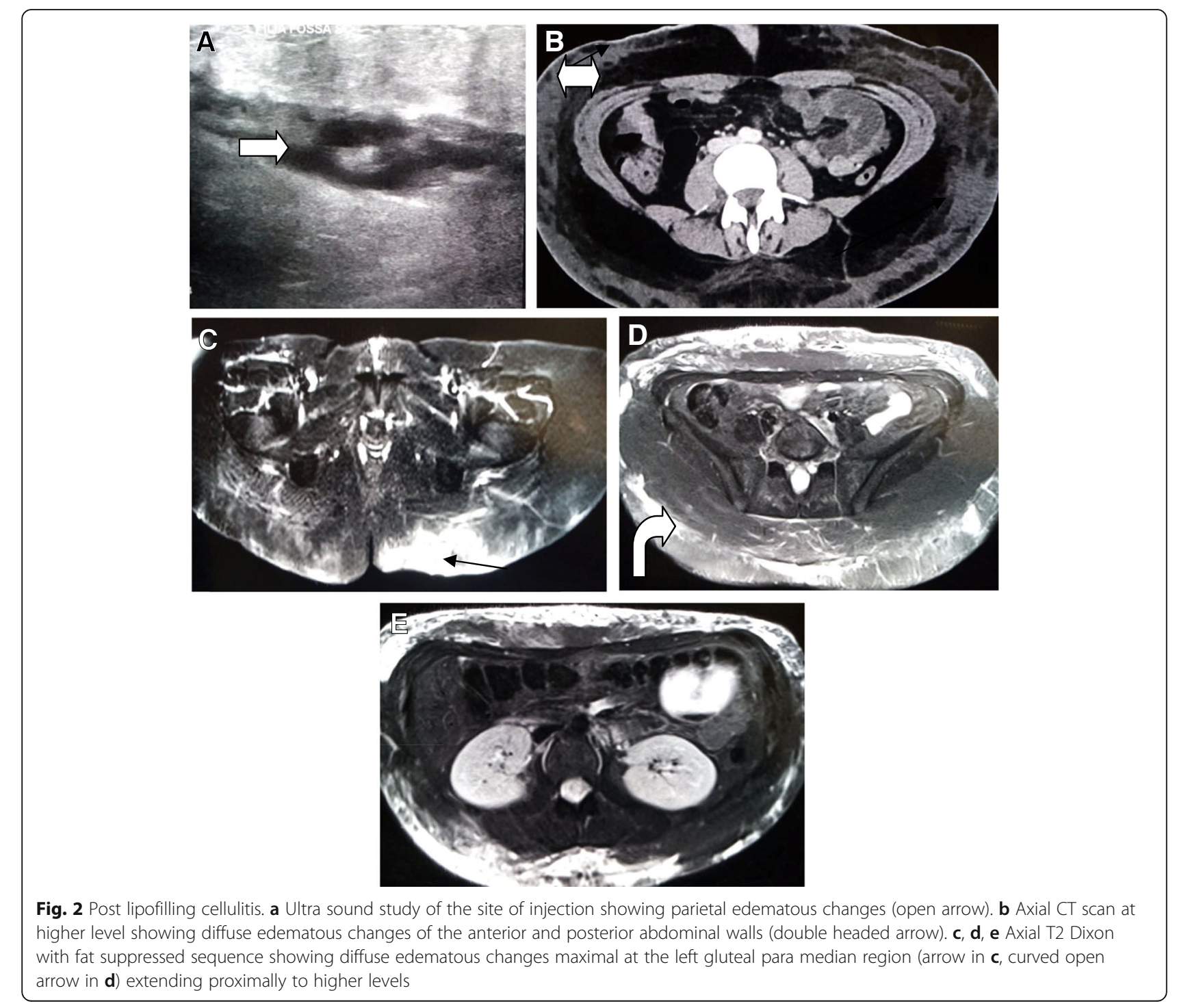


and 20 patients $(41.6 \%)$ between 50 less than 60 years (Table 1).

Of the 48 patients, 44 patients $(91.6 \%)$ underwent facial injectable fillers injection and 4 patients (8.3\%) underwent gluteal region fillers injection (Table 1). The imaging was indicated for assessment of the fillers and potential complications in 22 patients out of 48 patients (45.8\%), while in the remaining 26 patients (54.1\%), imaging was done for other indications with incidental discovery of the fillers confirmed by history, classic morphological features, and expected anatomical locations (Table 1, Fig. 1).
Most of the fillers, due to high water contents, displayed T1WI hypointense, T2WI hyperintense signal, and no suppression of signal on fat suppressed sequence; in the contrast enhanced sequences, only peripheral rim enhancement may be encountered mostly due to related tissue reaction (Table 2). Although helping in detection, such imaging features render characterization of the types of injectables more difficult; in this study, only lipofilling could be characterized based on the characteristic MRI signal of the injectable fat and signal suppression in the fat suppressed sequence.
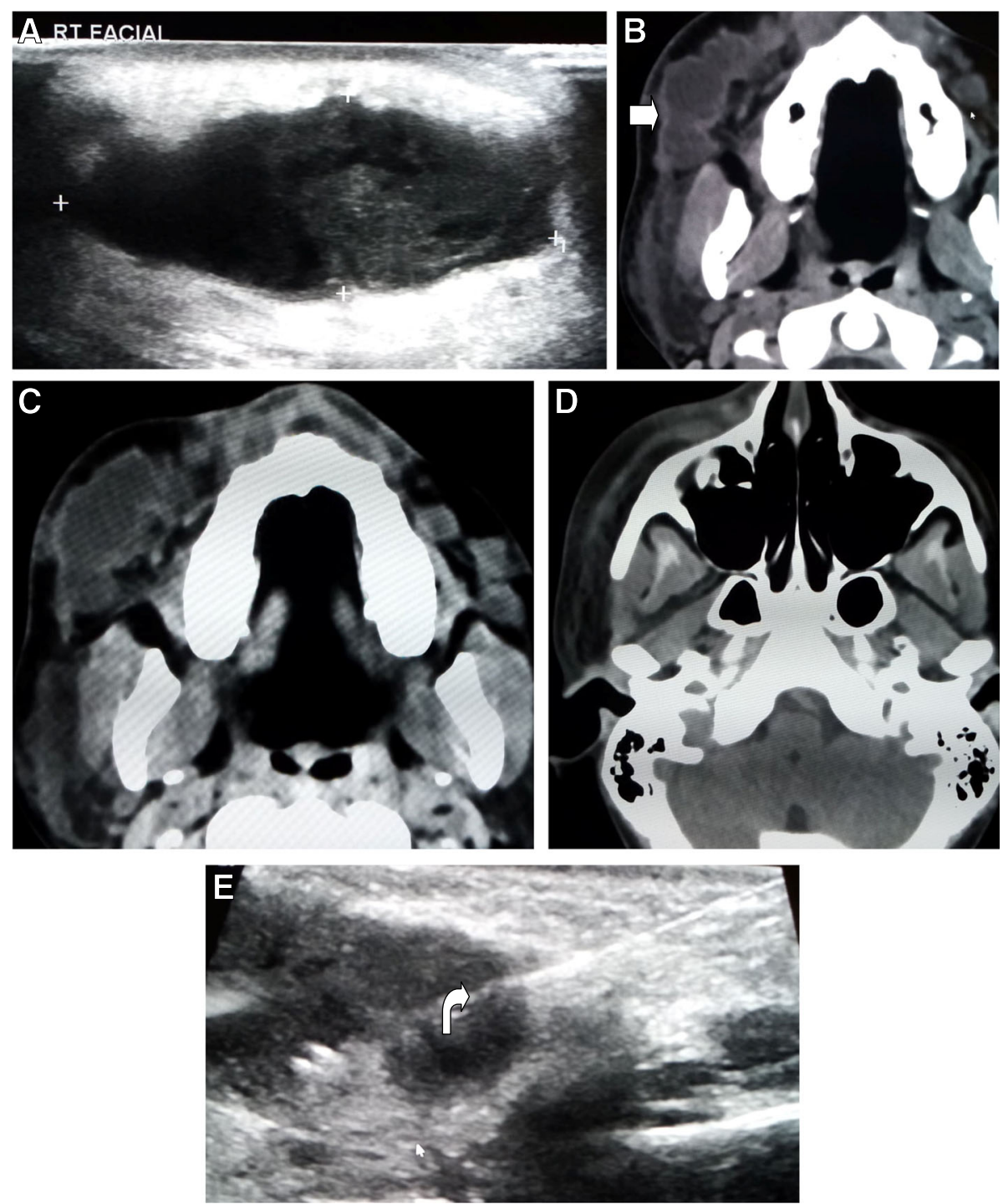

Fig.3 a Sonographic scan of the right side of 35 years old female patient face with pain, signs of infection following filler injection, the transverse scan showed loculated fluid collection with internal echoes. b, c, d Axial CT scans show loculated collection at the anatomical site of the buccal space extending anterior to the masseter muscle with soft tissue swelling inferiorly (arrow). e Ultra sound guided aspiration was done (curved arrow) with aspiration of $10 \mathrm{cc}$ pure pus confirming abscess formation on top of previous filler injection 
The most common locations of fillers include the subcutaneous tissue of the naso-labial fold, medial and middle superficial cheek fat compartments, and peri-oral region including the superior and inferior jowl fat compartments.

We noted complications in 11 patients $(22.99 \%)$, six patients (6/11) (54.54\%) presented with single complication, while in the remaining five patients (5/ $11,45.45 \%)$, more than 1 complication was noted (Table 3); collectively, the noted complications in our study were distributed as the following:

Asymmetry with over-injection was noted in seven patients (7/11, 63.63\%); infection was noted in three patients (3/11, Fig. 2); two of them developed

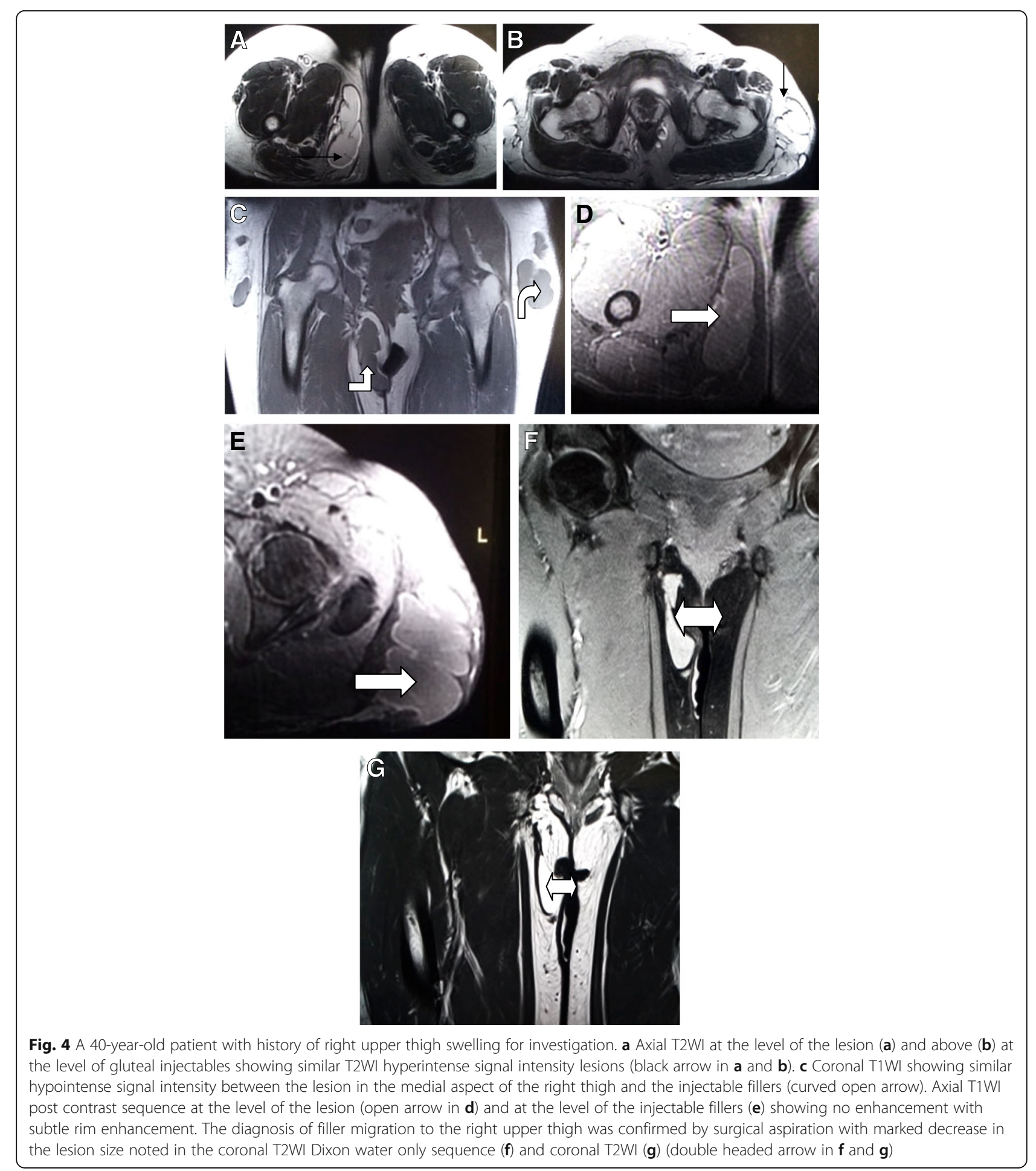



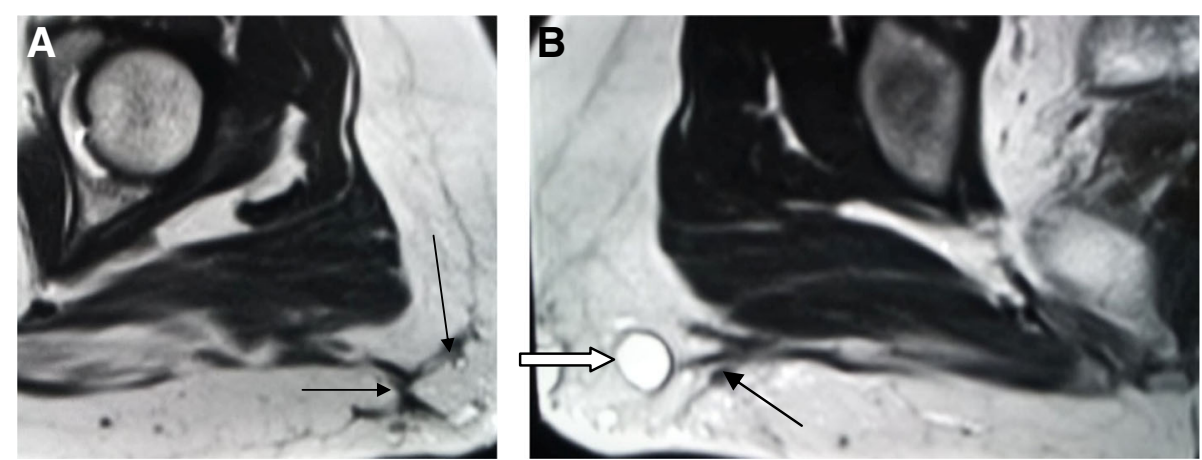

Fig. 5 Axial T2WI MRI 1 year following left (a) and right (b) gluteal region filler injection with subcutaneous linear and curvilinear hypointense areas impressive of fibrosis (arrow) close to the injected fillers (open arrow)

subcutaneous abscesses (Fig. 3); migration of the injectable was noted in four patients (4/11, Fig. 4); fibrosis and scarring were noted in two patients $(2 / 11)$ (Fig. 5, Table 3).

\section{Discussion}

Injectable fillers can cause diagnostic dilemma, notably in patients with metastatic/lymphoma diagnostic work up; the patient may not remember the procedure or know the injected filler type; complicated fillers may resemble recurrent cancer in already diagnosed head and neck oncologic patients; furthermore, facial fillers may mask underlying neoplasms. Ten known patients in this study with history of lymphoma underwent diagnostic work up for lymphoma raising the concern of important diagnostic differentiation between lymphomatous infiltration and injectables; diffusion weighted imaging and contrast study are the keys for differentiation with expected diffusion restriction and contrast enhancement of the lesion matrix in neoplastic lesions (Fig. 6). The expected high cellularity in metastatic and malignant neoplastic lesions with cause restricted diffusion pattern in the DWI sequence. The cutoff ADC value in the literature was $0.9 \times 10^{-3} \mathrm{~mm}^{2} / \mathrm{s}$. Fillers will not show high cellularity nor diffusion restrictions; noncomplicated fillers will show minimal peripheral enhancement due to related tissue reaction, while the neoplastic lesions/metastatic lesions will show positive enhancement due to cellular matrix.

Contrast enhanced MRI study is found to be reliable imaging tool for accurate localization of the injectable fillers and identification of the related complications. In this study, MRI was used in 46 patients, and CT was used in 2 patients with abscesses managed with no need for MRI assessment; most of the published literature discussed the role of MRI study in evaluation of the injectable fillers and potential complications [9]. Other studies used ultra-sonographic assessment only in fillers assessment. Schelke et al. [10] used this modality to describe the properties of several semipermanent and permanent fillers; most of fillers had anechoic to hypoechoic aspect, with distinct echogenic walls observed on scans.
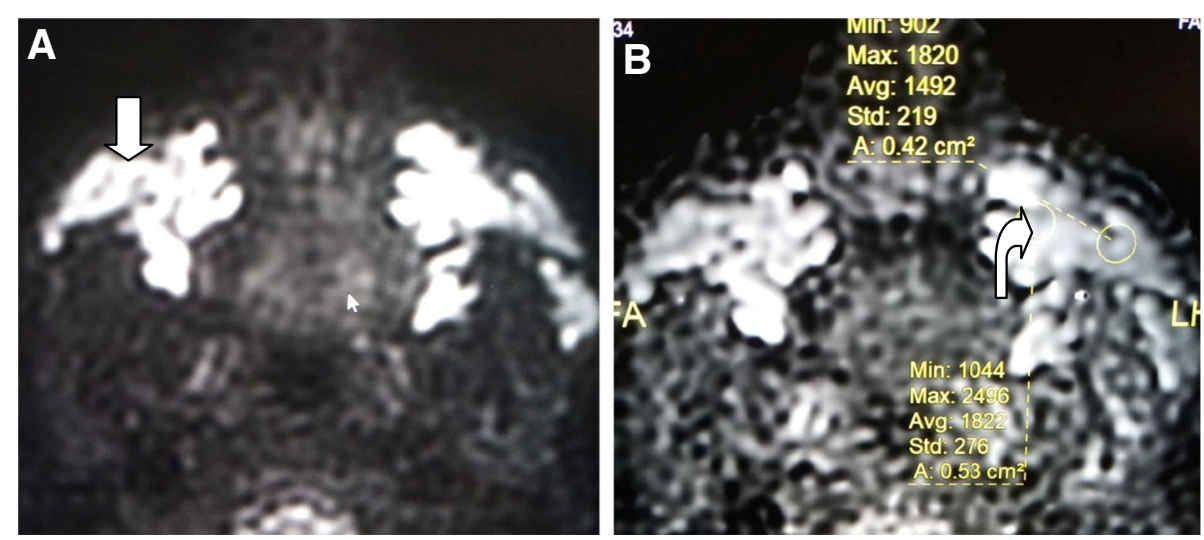

Fig. 6 A 46-year-old female patient with history of lymphoma on remission, subjected to routine follow-up. DWI (a) and corresponding ADC map (b) showing facilitated diffusion on the medial and middle superficial cheek fat compartment with mean ADC value $1.4 \times 10^{-3} \mathrm{~mm}^{2} / \mathrm{s}$ excluding possibility of lymphomatous infiltration (open arrow in $\mathbf{a}$, curved arrow in $\mathbf{b}$ ) 
The main indication for imaging in the published studies was for assessment of the fillers; we noted 26 patients subjected to MRI studies for other indications; 10 were subjected to MRI study in the diagnostic work up of lymphoma, and 16 were subjected to MRI in the diagnostic work up of headache with incidentally noted fillers. The imaging features of fillers should be considered especially in oncologic patients with metastatic work up, and radiologists should be familiar to their features and characteristic locations. Kadouch et al. [2] in their study focused more upon the clinico-radiological correlation and clinically detected complication in comparison to the MRI results; they focused upon the injection sites assessing 96 injection sites in 32 patients.

Mundada et al. [11] claimed that they can differentiate different types of fillers according to their MRI signature; to our knowledge most of fillers-due to high water contents-share similar MRI signal. The autologous fat noted in one patient with history of lipofilling showed characteristic fat signal.

Complications noted in this study were asymmetry, infection with cellulitis and abscess formation, migration, and scarring. Leyva et al. [12] published a case of gluteal granuloma formation following gluteal augmentation with liquid silicon.

Tal et al. [8] reported in their study about facial filler complications in fourteen patients, four cases with foreign body granulomas based on total enhancement of the lesions and two cases of allergic reaction based on the patchy signal and related stranding of fat planes.

This study had few limitations, the relative small number of cases compared to other studies; we believed complete characterization of the filler type based on MRI features is difficult because most fillers share the high water content signal; to our knowledge, complete characterization of the type of fillers based on MRI is difficult as most of fillers show similar signal characteristics, which is not in agreement with few other studies [13-15], and some complications are not included in the study like foreign body granulomas and allergic reactions. Important noted limitation was for symmetry/asymmetry assessment; we thought there is technical clinical limitation in reaching full symmetric appearance may be due to subjective factors and patient satisfaction. Yet, there are multiple merits for the technique including stimulation of collagen production and tightens loose skin with delayed aging process.

We thought that each radiologist should be familiar with injectable filler imaging features and potential complications notably in cases of metastatic work up.

\section{Conclusion}

MRI is an effective tool for evaluation of facial and gluteal region fillers with delineation of their imaging features and related potential complications.

Differentiation between fillers and neoplastic or granulomatous lesions could be accurately done with crosssectional imaging.

\section{Abbreviations}

MRI: Magnetic resonance imaging; CT: Computerized tomography; US: Ultrasonography; ADC: Apparent diffusion co-efficient; FS: Fat suppression;

FSE: Fast spin echo

\section{Acknowledgements}

None

Author's contributions

MA reported the cases and drafted the manuscript. The author read and approved the final manuscript.

Funding

This study had no funding from any resource.

Availability of data and materials

The data sets used and/or analyzed during the current study are available from the corresponding author on reasonable request.

Ethics approval and consent to participate

A written informed consent was obtained from all patients included in this study to participate in this study. Approval for this study was obtained from the Research Ethics Committee of our institute. All study procedures were carried out in accordance with the Declaration of Helsinki regarding research involving human subjects....IRB:00012098.

Consent for publication

All the patients included in this study gave written informed consent to publish the data contained within this study.

\section{Competing interests}

There are no conflicts of interests. The author declares that they have no competing interests.

Received: 28 April 2020 Accepted: 9 July 2020

Published online: 21 July 2020

\section{References}

1. Funt D, Pavicic T (2015) Dermal fillers in aesthetics: an overview of adverse events and treatment approaches. Plast Surg Nurs 35(1):13-32

2. Kadouch J, Tutein Nolthenius C, Kadouch D et al (2014) Complications after facial injections with permanent fillers: important limitations and considerations of MRI evaluation. Aesthet Surg J 34(6):913-923

3. Di Girolamo M et al (2015) MRI in the evaluation of facial dermal fillers in normal and complicated cases. Eur Radiol 25(5):1431-1442

4. Persichetti $P$ et al (2013) Dermal filler complications from unknown biomaterials: identification by attenuated total reflectance spectroscopy. Plast Reconstr Surg 131(4):597e-603e

5. Ginat DT, Schatz CJ (2013) Imaging features of midface injectable fillers and associated complications. Am J Neuroradiol 34(8):1488-1495

6. Feeney JN, Fox JJ, Akhurst T (2009) Radiological impact of the use of calcium hydroxylapatite dermal fillers. Clin Radiol 64(9):897-902

7. Wollina U, Goldman A (2013) Dermal fillers: facts and controversies. Clin Dermatol 31(6):731-736

8. Tal S, Maresky HS, Bryan T et al (2016) MRI in detecting facial cosmetic injectable fillers. Head Face Med 12(1):27

9. Khawaja AZ et al (2015) Revisiting the risks of MRI with Gadolinium based contrast agents - review of literature and guidelines. Insights Imaging 6(5): 553-558 
10. Schelke LW, Van Den Elzen HJ, Erkamp PP et al (2010) Use of ultrasound to provide overall information on facial fillers and surrounding tissue. Dermatol Surg 36(suppl 3):1843-1851

11. Mundada P, Kohler R, Boudabbous S et al (2017) Injectable facial fillers: imaging features, complications, and diagnostic pitfalls at MRI and PET CT. Insights Imaging 8(6):557-572

12. Leyva A, Tran T, Warden D et al (2018) Filler migration and granuloma formation after gluteal augmentation with free-silicone injections. Cureus

13. Becker M, Balague N, Montet X et al (2015) Hyaluronic acid filler in HIVassociated facial lipoatrophy: evaluation of tissue distribution and morphology with MRI. Dermatology 230(4):367-374

14. Van Rozelaar L, Kadouch JA, Duyndam DA et al (2014) Semipermanent filler treatment of HIV-positive patients with facial lipoatrophy: long-term followup evaluating MR imaging and quality of life. Aesthet Surg J 34(1):118-132

15. Pavicic T (2015) Complete biodegradable nature of calcium hydroxylapatite after injection for malar enhancement: an MRI study. Clin Cosmet Investig Dermatol 8:19-25

\section{Publisher's Note}

Springer Nature remains neutral with regard to jurisdictional claims in published maps and institutional affiliations.

\section{Submit your manuscript to a SpringerOpen ${ }^{\circ}$ journal and benefit from:}

- Convenient online submission

- Rigorous peer review

- Open access: articles freely available online

High visibility within the field

- Retaining the copyright to your article

Submit your next manuscript at $\boldsymbol{\nabla}$ springeropen.com 